\title{
Use of Hardwood Species (Robinia pseudoaccacia) from Short- rotation Plantations as Raw Material in Particleboards
}

\author{
J. Lawrence Tene Tayo ${ }^{1}$, Achale Travolta Achale ${ }^{2} \&$ Markus Euring ${ }^{1}$ \\ ${ }^{1}$ Department of Forest Botany and Tree Physiology, Georg-August-University of Goettingen, Germany \\ ${ }^{2}$ Department of Molecular Wood Biotechnology and Technical Mycology, Georg-August-University of \\ Goettingen, Germany \\ Correspondence: Markus Euring, Department of Forest Botany and Tree Physiology, Georg-August-University of \\ Goettingen, Germany, E-Mail: meuring@gwdg.de
}

Received: March 10, 2020

Accepted: March 28, 2020

Online Published: April 3, 2020

doi:10.5539/jmsr.v9n1p18

URL: https://doi.org/10.5539/jmsr.v9n2p18

\begin{abstract}
The problem of climate change, coupled to the propagation of wood diseases (bark beetles for example), is leading to a shortage in softwood supply for the particleboard industries. Furthermore, the recent changes in the German forest policies which promote the conversion of coniferous forest into mixed stands are likely to enhance this phenomenon. There is, therefore, a growing need for research on possibilities of substituting the softwood with hardwood and other alternative material. For the first time, young six to seven years old Black locust (Robinia pseudoaccacia) stems from a short-rotation plantation were used at a laboratory scale with the objective of assessing the suitability of particleboard production. Four different variants were produced using different resin types: UF K350, UF K340, albumin, and PMDI, with a target density and thickness of $650 \mathrm{~kg} / \mathrm{m}^{3}$ and $20 \mathrm{~mm}$ respectively for each board. The boards were tested regarding their mechanical (modulus of rupture, modulus of elasticity and internal bonding), physical (water absorption and thickness swelling) properties according to the European standard (EN 310, EN 317 and EN 319), and their formaldehyde content and emission following the EN 120 and EN 717. Industrial particles were used as reference material for the purpose of comparison. Promising bending strength was obtained with UF resins-bonded boards. The modulus of elasticity of all four variants fulfilled the EN 2003 requirements. The internal bond of the UF resins-bonded boards also met the general product standard, with values above $0.35 \mathrm{~N} / \mathrm{mm}^{2}$. The bending strength and the internal bonding strength properties of the UFbonded boards were superior to that of the reference boards produced with the industrial particles. Based on these results, black locust is a potential substitute for softwood in particleboard production and can be used in the industry as alternative raw material for panel production.
\end{abstract}

Keywords: Particleboard, Mechanical and physical properties, Black locust, Hardwood, climate change

\section{Introduction}

The continuously changing raw material situation has always been one of the major driving forces for constant innovation in the wood-based panel sector and the high variability of the wood raw material in the wood-based panel industry constitutes a challenge not known by many other industries (Thoemen et al., 2010). Although one notices a great increase in logging $\left(53,49\right.$ million $\mathrm{m}^{3}$ in 2017 compared to 64,55 million $\mathrm{m}^{3}$ in 2018 according to Statistisches Bunddesamt), there is a decrease in the availability of raw material for the wood-based panel industries due to competition with other sectors and the continuously growing demand (Friese et al., 2015). The actual demand for wood is about 235 million $\mathrm{m}^{3}$ per year, while the potentially mobilized and available amounts to 100 million $\mathrm{m}^{3}$ per year. There is then a huge gap to fill, which makes the wood costs to rise, demand surpassing supply (Kharazipour 2005). The actual tendency is that more pressure will be put on the forest resources. In addition to the growing demand for conifer wood for material uses, the wood industries are also facing growing competition for wood from the consumers seeking to use wood for energy (Friese et al., 2015). According to Mantau (2010), the estimated energy use of wood in Europe is currently equal to that used for material application and will be higher by 2030 (56.5\% of the total wood supply) and the forest woody biomass will decrease from $62 \%$ in 2020 to $59 \%$ in 2030 . This means less wood will be available for the industries in the future. Moreover, the long-term supply of softwood in threatens by climatic changes and the spray of bark beetles that destroy conifer forests. The new developments in forest policy advocate the establishment of mixed forest to overcome the effects 
of climate change. Environmental policies and regulations are more towards the exclusion of more forests from wood production and energy policies increasingly encourage the use of biomass, including wood (FAO, 2009). The proportion of conifers on the wood market is likely to decrease in the coming decades. The growing scarcity of softwood calls for new approaches involving the use of different wood raw material and the development of innovative technologies for the more efficient exploitation of the available wood material (Friese et al., 2015). This situation has raised questions on the sustainability of forest management in Germany (Mantau, 2008) and potential means to address the issue, such as the cascade utilisation of wood resources (Friese et al., 2015) which follows a biorefinery concept, have been proposed. Improve efficiency, improve productivity and light-weight material production are some other solutions, as well as the use of hardwood material from short-rotation plantations or coppice. Innovation is, therefore, a priority to achieving a long-term sustainable production and supply of wood-based panels. However, little studies have been done so far on the possibility of using hardwood in particleboard manufacturing and many still believe that the low workability, the natural structure of the hardwood fibers and the high extractives content make them not suitable. Some species like poplar and beech have shown good results and further investigations need to be done to determine which other hardwood species can achieve comparable physical-mechanical properties and to which extend (proportion) softwood can could be substituted without jeopardizing the properties of the end-product.

\subsection{Objective}

The aim of the present study is to contribute to the sustainability of the wood-based panel industry through the development of particleboards using alternative hardwood species. More specifically, it consists of investigating the suitability of Robinia wood from short-rotation plantations as material for particleboard production, using four different binder systems.

\section{Material and Method}

The Black locust wood material used for this experiment was collected from six to seven years old experimental plots situated in Rheinshof and Deppoldshausen, two districts located in the neighborhood of Göttingen. The Black locust chips needed for the production of the particleboards were produced in the pilot plant of the Büsgen-Institute, University of Göttingen. Industrially produced particles (a mixture of different softwood species) obtained from the company Pfleiderer Holzwerkstoffe GmbH located in Gütersloh, were used as reference material.

\subsection{Wood Particles Preparation}

Because of the bark's effect on the particleboard's physical-mechanical properties such as thickness swelling, linear expansion, and IB strength, it is ideal to get reed of the bark before processing. The young Black locust stems were manually debarked (at least at $98 \%$ ) before being processed into particles, to ensure the quality of the end products. The primary breakdown was done using a vertical drum hacker from the company Delachaux GmbH, Offenbach, model PML 1 150/250. The chips obtained went next through a knife ring flacker (Offenbach, model PML 1 150/250) from the company Delachaux $\mathrm{GmbH}$ ) which broke them into wood particles. These particles were screened using a Whirling sieve (ALLGAIER TSM 1200/2) from the company ALLGAIER -Werke GmbH equipped with changeable screening inserts. Oversize particles (particles that could not pass through a mesh with $6.3 \mathrm{~mm}$ apertures) and dust (particles passing through a mesh with $1 \mathrm{~mm}$ apertures) were removed. The material was next oven-dried to $3 \%$ moisture content (MC) and stored in polyethylene bags.

\subsection{Particleboard Production}

The three-layer particleboards were produced at a laboratory scale in the pilot plant of the Büsgen-Institute, GeorgAugust University of Göttingen. Four variants were produced using four different resins: two different commercial-grade UF-resins of the Kaurit group K350 and K340 in liquid form, albumin (blood powder from pork provided by Fritz Häcker GmbH \& Co.KG) and a commercial-grade Isocyanate-based resin - PMDI (I-Bond PB em 4352) supplied by Huntsman Holland BV. For each of the four different variants, two types of boards were produced: one using Robinia particles and the other using industrial particles. Table 1 gives details about the production parameters. 
Table 1. Production and resin parameters

\begin{tabular}{lll}
\hline Variant & Variables & Constants \\
\hline V1 & UF K350 & Press time: 4 min \\
& $10 \%$ on SL, $8.5 \%$ CL & Press time factor: $12 \mathrm{~s} / \mathrm{mm}$ \\
V2 & UF K340 & Pressure: 200 bars \\
& $10 \%$ on SL, $8.5 \% \mathrm{CL}$ & Temperature: $200{ }^{\circ} \mathrm{C}$ \\
V3 & albumin & Hardener: $1.5 \%$ for both CL and SL \\
& $10 \%$ on SL, $8.5 \% \mathrm{CL}$ & Wax: $2.0 \%$ \\
V4 & PMDI & Board type per variant: 2 \\
& $2.5 \%$ on SL, $2.0 \% \mathrm{CL}$ & Board per type: 2 \\
& & Number of layers: 3 \\
& & Board format: $700 \mathrm{x} 460 \times 20 \mathrm{~mm}$ \\
& & Thickness: $20 \mathrm{~mm}$ \\
& Target density: $650 \mathrm{~kg} / \mathrm{m}^{3}$ \\
\hline
\end{tabular}

Note: No curing agent was used for albumin-bonded boards

CL: Core layer; SL: Surface layer.

The necessary amount of material was weighed to obtain a final target density of $650 \mathrm{~kg} / \mathrm{m}^{3}$. The target mat moisture content was $10 \%$. First, a $2 \%$ solution of water-repelling agent (50\% solid content) was sprayed. A $1.5 \%$ of ammonium sulfate ( $40 \%$ solid content) was added to the resins (except for albumin) prior to spraying. The amount of resin and wax was added based on the oven-dry mass of the material. The resins were applied to the furnish using an atomizing nozzle with a middle size of $1.5 \mathrm{~mm}$ (model A11 from Krautsberger company). The wax was always sprayed before the resin-hardener mixture. After blending, the $\mathrm{MC}$ was measured using an electronic moisture analyzer and the mass of material needed for each board's layer calculated according to the MC. Rectangular mats were hand-formed on aluminum press plates using an aluminum frame. After a manual prepress, the aluminum frame was removed and the mats hot-pressed without stoping in a computer-controlled laboratory scale hydraulic single-opening hot-press (Siempelkamp Hydraulic Lab Press A 308/1988) for 4 min with 200 bar pressure at 200 degree Celsius of temperature. The boards were allowed for 24 hours at room temperature. They were next trimmed to avoid edge effect and sanded on both sides by using a wide belt sanding machine (Felder type FW $950 \mathrm{C}$ ) and cut into $460 \mathrm{~mm} \times 50 \mathrm{~mm} \times$ thickness. Board conditioning took place in a climate chamber at 20 degree Celsius and $65 \%$ relative humidity for one week prior to testing of the different physical-mechanical parameters.

\subsection{Testing the Properties of the Produced Particleboards}

\subsubsection{The Mechanical Properties}

The determination of the mechanical properties was made according to the European standards EN 323, 1993; EN 310, 1993 and EN 319, 1993 for density profile, bending strength (BS) and internal bonding (IB). For the test of the BS, a universal testing machine from ZWICK/ROELL (type 10) was used to carry out the bending strength and the modulus of elasticity test. Particleboards from each variant were cut into $430 \mathrm{~mm} \times 50 \mathrm{~mm}$ x thickness pieces. 6 samples from each board were used to test the BS of each board. The thickness and width of each test piece were measured with a caliper and entered in the machine's software. The adjustable supports of the testing machine were made to be $20 \mathrm{x}$ board thickness away from each other and the test pieces were one after another loaded perpendicularly to the supports and making sure the impact will be in the middle of the test piece. After testing the BS, the samples were cut into $50 \mathrm{~mm} \times 50 \mathrm{~mm}$ x thickness pieces. The density of 30 samples of $50 \mathrm{~mm}$ x $50 \mathrm{~mm}$ x thickness was measured using a caliper and an electronic scale. From these samples, eight were chosen for the IB test. These eight were those with a density close to the board's target density $\left(650 \mathrm{~kg} / \mathrm{m}^{3}\right)$. We also make sure that the mean density value of the eight pieces chosen was the closest possible to the board's target density. They were glued between two loading test blocks made of plywood and loaded onto the testing machine.

\subsubsection{The Physical Properties}

The density profile of each board was tested using a GreCon x-ray densitometer (GreCon DAX-500). Prior to the IB test, six samples from those selected each board for the IB test were used for the density profile. The sizes were measured, the samples entered in the machine's software and the test pieces loaded into the densitometer sample holder. The profiles were generated and saved in the software system. Weight and thickness of 8 test pieces of 50 $\mathrm{mm} \times 50 \mathrm{~mm}$ x thickness were recorded with an electronic scale and a caliper. They immersed in a clean water bath, each test piece separated from the other by a plastic or a metal barrier. They were made to stay at least 2 to $3 \mathrm{~cm}$ below the water with a metal mesh above. After spending 24 hours immersed in water, they were weighted 
and the thickness measured again. The water absorption and the thickness swelling were subsequently calculated and expressed as a percentage of the original mass or thickness.

\subsection{Formaldehyde Emission (FE) and Formaldehyde Content (FC) of the Particleboards}

The flask method (EN 717-3) and the perforator method (EN 120) were used in the present study, to assess the FE and the FC. Prior to this, the moisture content of the boards was determined according to EN 322 (1993).

\subsubsection{Determination of Formaldehyde Emission using the Flask Method (EN 717-3)}

In the $500 \mathrm{ml}$ polyethylene flask containing $50 \mathrm{ml}$ of demineralized water (meant to absorb the emitted formaldehyde during the process), approximately $20 \mathrm{~g}$ (three pieces of $25 \mathrm{~mm} \times 25 \mathrm{~mm}$ ) was made to hang from a stainless-steel hook fixed to the cover of the flask. The flasks were carefully closed and put in an oven at 40 degree Celsius for 24 hours. After this incubation time, the flasks were taken out and allowed to cool to room temperature. $10 \mathrm{ml}$ of absorption solution containing formaldehyde was pipetted into $50 \mathrm{ml}$ stopper flasks and the reagents were added $(10 \mathrm{ml}$ of acetylacetone and $10 \mathrm{ml}$ of ammonium acetate). For the control (blank), $10 \mathrm{ml}$ of demineralized water was used and the same number of reagents was added. These samples were next put in a warm bath at a constant temperature of $40^{\circ}$ Celsius for 15 minutes after which they were removed and left to cool in dark for one hour. A spectrophotometer Typ Libra S11/S12 from BIOCHROM, Cambridge set at $412 \mathrm{~nm}$ wavelength was used to read the extinction values.

\subsubsection{Determination of Formaldehyde Content Using the Perforator Method (EN 120)}

Approximately $110 \mathrm{~g}$ of board cut into $25 \mathrm{~mm}$ x $25 \mathrm{~mm}$ pieces were put in $1000 \mathrm{ml}$ Erlenmeyer flasks and $600 \mathrm{ml}$ of toluene was added. These were placed on heating plates and connected to the perforator system. $920 \mathrm{ml}$ of demineralized water was poured in the perforator and a spiral condenser was next air-tied with Teflon seals connected to the perforator. A gas absorption tube was next connected on one end to the condenser and a $250 \mathrm{ml}$ Erlenmeyer flask filled with $200 \mathrm{ml}$ of demineralized water connected to the other end. The whole system was switched on and the extraction process carried out for two hours. After that, the system was switched off and left to cool to room temperature. The water contained in the perforator was drained into a $2000 \mathrm{ml}$ volumetric flask through the perforator's tap and the perforator was rinsed twice each with $350 \mathrm{ml}$ of demineralized water. After thorough shaking, $10 \mathrm{ml}$ of solution was pipetted into $50 \mathrm{ml}$ stopper flasks. The same steps in the previous section were followed to determine the extinction values. The following formula was used to calculate the formaldehyde content in (mg HCHO/100 g).

\section{Results and Discussions}

\subsection{Mechanical Properties}

\subsubsection{Density and Density Profile of the Particleboards}

Although the density profile alone cannot predict the board mechanical properties, the inter-particle bond and the layering factor most significantly influence the strength properties of particleboard. However, the density profile can help to predict or to make a hypothesis on these mechanical properties and one can assume that, the higher the maximum density, the higher the MOR strength; and the higher the minimum density, the higher the IB strength. The density of the surface layers of each board was observed to be higher than the density of the core layer which is typical for particleboards. Figure 1 shows the density profile of the boards bonded with UF resin (K350), albumin and PMDI. For the UF K350-bonded, the maximum densities were $795.9 \mathrm{~kg} / \mathrm{m}^{3}$ and $872.4 \mathrm{~kg} / \mathrm{m}^{3}$ and the minimum $561.5 \mathrm{~kg} / \mathrm{m}^{3}$ and $550.7 \mathrm{~kg} / \mathrm{m}^{3}$ respectively. The industrial particles-based particleboards bonded with blood albumin had the highest core layer density $\left(913.7 \mathrm{~kg} / \mathrm{m}^{3}\right)$, followed by the Robinia particles-based boards bonded with the same resin type $\left(826.0 \mathrm{~kg} / \mathrm{m}^{3}\right)$. The minimum core layer density was also observed in same particleboard variants, $550.3 \mathrm{~kg} / \mathrm{m}^{3}$ and $534.7 \mathrm{~kg} / \mathrm{m}^{3}$ for Robinia particles-based and industrial particles-based boards respectively. Particleboards from the Robinia particles showed higher density values throughout the core layer. 


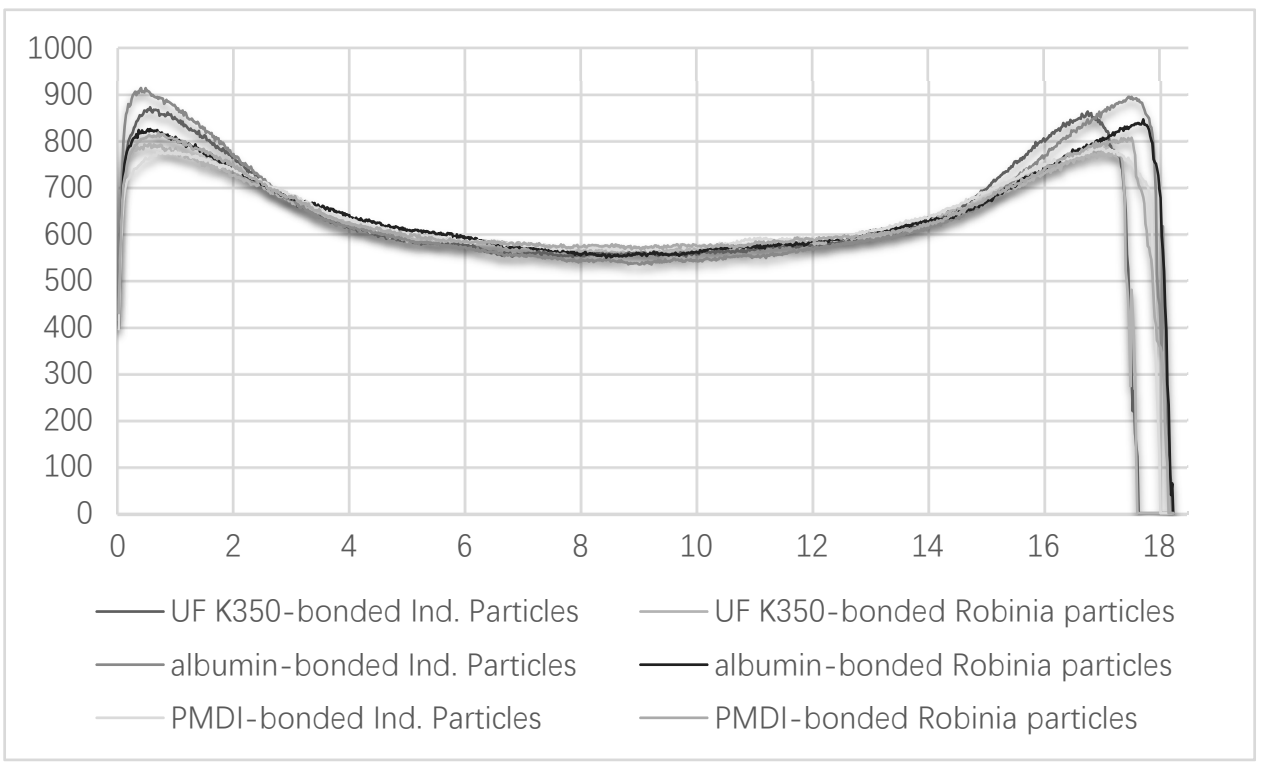

Figure 1. Density profile of the produced boards

\subsubsection{Bending Strength (BS) EN 310}

The bending strength (BS) is the most important mechanical property of a wood-based panel, especially in the furniture industry since the quality of the end products mostly depends on the board's strength. Figure 2 presents the BS values of the laboratory particleboard produced. Except for UF K350-bonded, all the other Robinia-based particleboards gave BS values below the EN 310 (1993) standard requirements for particleboards of $650 \mathrm{~kg} / \mathrm{m}^{3}$ density and 13 to $20 \mathrm{~mm}$ thickness $\left(11 \mathrm{~N} / \mathrm{mm}^{2}\right)$. The average BS value for UF K340-bonded was slightly lower than the EN 310 norms. The Robinia-based Albumin- and PMDI-bonded boards had the lowest BS values (7.91 $\mathrm{N} / \mathrm{mm}^{2}$ ). The reference industrial particle-based boards showed the same trend, except from PMDI- bonded boards which gave the highest BS values obtained in this study $\left(13.6 \mathrm{~N} / \mathrm{mm}^{2}\right)$. Together with the UF K350-bonded boards, they had BS values above the EN 310 standards.

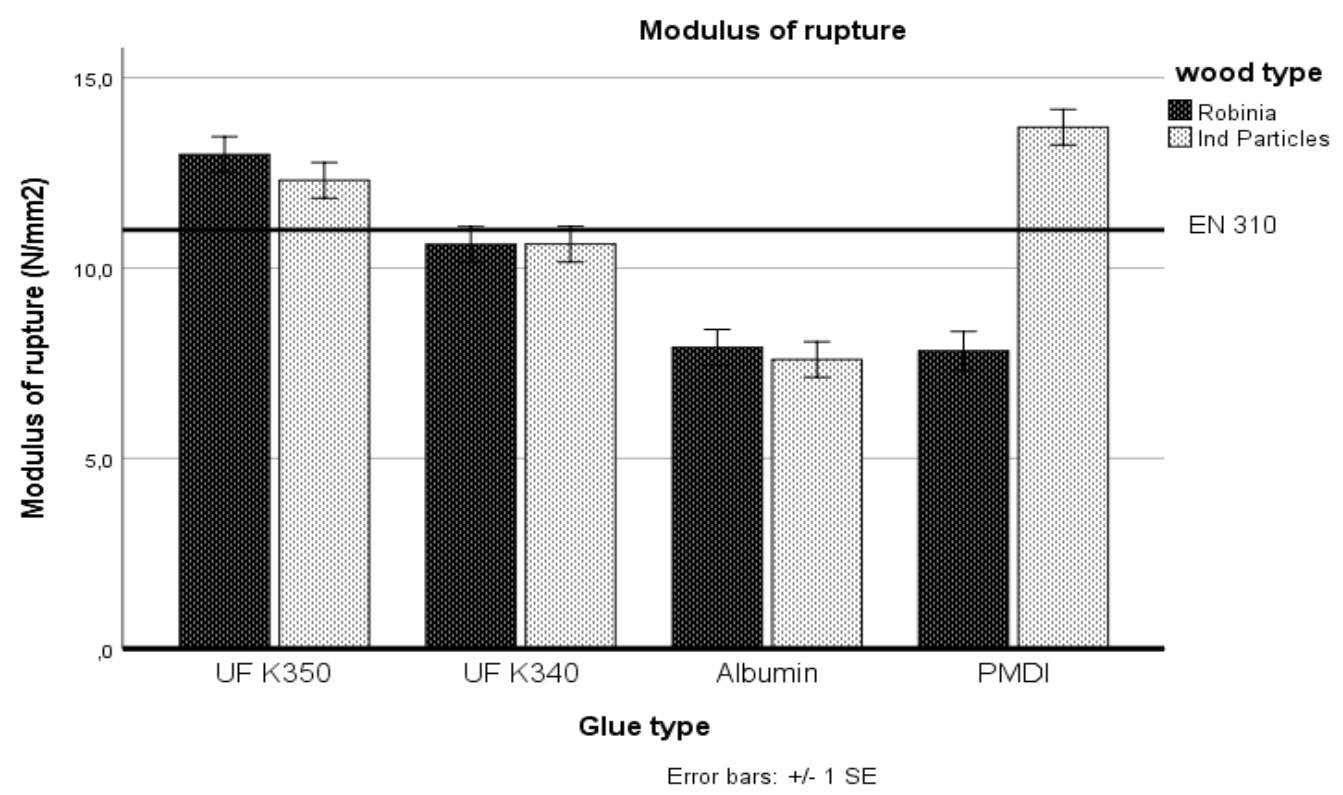

Figure 1. Modulus of rupture (bending strength) of the laboratory particleboards 
Many factors such as wood species, particle geometry, compactness ratio, wood fiber length, production parameters, etc., influence the BS in particleboards. During production, particles are obliquely deposited, which leads to a vertical cross-linking. This phenomenon is most likely when the aspect ratio of the particles is low and might result in poor BS performances. Though no significant difference was found across species except for particleboards bonded with PMDI, the resin type had a significant effect on the BS. The results obtained here UF resins corroborate with Barboutis and Philippou (2005) findings. They obtained BS values between $10.01 \mathrm{~N} / \mathrm{mm}^{2}$ and $13.48 \mathrm{~N} / \mathrm{mm}^{2}$ with five hardwood species (Arbutus unedo, Quercus ilex, Quercus coccifera, Erica arborea, and Philyrea latifolia) bonded with $8 \%$ dry weight E2 UF resin. Gamage et al. (2009) also produced similar results $\left(9,42 \mathrm{~N} / \mathrm{mm}^{2}\right)$ from tropical Eucalyptus sawmill residue using urea-formaldehyde resin (E1 resin) containing 63 to $65 \%$ solid. Surprising, the BS performance of the Robinia-based albumin-bonded boards was similar to that of PMDI-bonded ones. Most interesting were the BS values of the albumin-bonded boards. Though still having some old binders, albumin-bonded boards made from the industrial particles had lower BS values than their fellows made from the Robinia particles. Albumin has proved to be able to produce better results as those obtained here. Schmidt (2019) obtained $13.7 \mathrm{~N} / \mathrm{mm}^{2}$ from beech and birch bonded with albumin. This shows that albumin may be an important alternative, competitive and health-friendly since it contains no formaldehyde.

\subsubsection{Modulus of Elasticity EN 310}

The Young's modulus, a measure of the stiffness of an elastic material gives an idea of the deformation of a solid due to stress. Knowledge of elastic properties of these layers may be useful for more rational designing of structural members made of particleboards and for analyzing stresses and deformations occurring in these members (Wilczy'nski and Kociszewski, 2012). Together with the MOR, they determine the load-bearing capacity of particleboards. Results of the modulus of elasticity in figure 3 showed the same trend as the bending strength. the Robinia-based particleboards bonded with UF resins had MOE values above the EN 312 norms $\left(1500 \mathrm{~N} / \mathrm{mm}^{2}\right)$, $\left(2190 \mathrm{~N} / \mathrm{mm}^{2}\right.$ for UF K350 and $2035 \mathrm{~N} / \mathrm{mm}^{2}$ for UF K340). Albumin and PMDI had lower MOE values (respectively $1530 \mathrm{~N} / \mathrm{mm}^{2}$ and $1580 \mathrm{~N} / \mathrm{mm}^{2}$ ). Results of MOE were significantly affected by the raw material provenance, the industrial particles performing better with all four resin types providing MOE values above the EN 311 norm $\left(2420 \mathrm{~N} / \mathrm{mm}^{2}\right.$ for UF K350 and $2315 \mathrm{~N} / \mathrm{mm}^{2}$ for UF K340, $1630 \mathrm{~N} / \mathrm{mm}^{2}$ for UF albumin and 2425 $\mathrm{N} / \mathrm{mm}^{2}$ for UF PMDI). Across resin type, particleboards bonded with albumin and PMDI produced MOE values were lower than those bonded with UF K350 and UF K340. With the industrial particles, only the boards bonded with albumin proved to have a significantly low MOE value compared to others.

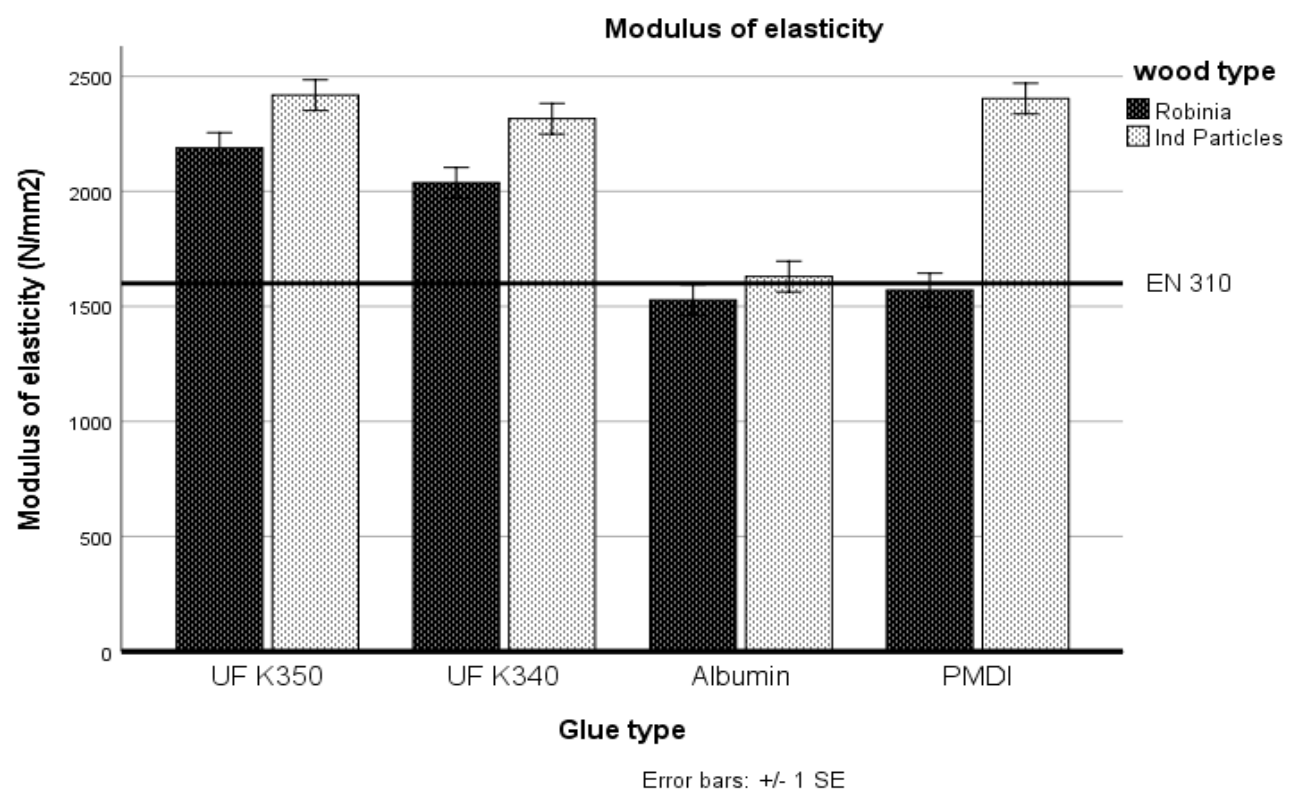

Figure 3. Modulus of elasticity of the laboratory particleboards

High-density species are not often good for particleboard production because of the resulting low compaction ratio (Navis Rofii et al., 2014). However, the results obtained here show that Robinia might behave well in particleboard production. Some species have proved to be as well suitable. Navis Rofii et al., 2014 obtained better MOE value 
from matoa (Pometia pinnata) bonded with PMDI resin. Wimmer et al. (2011) obtained MOE values between $2800 \mathrm{~N} / \mathrm{mm}^{2}$ and $3800 \mathrm{~N} / \mathrm{mm}^{2}$ from Oak, Beech and Poplar-based particleboards bonded with UF resin and PMDI.

\subsubsection{Internal bonding EN 319}

The particleboard's internal bond (IB) is a measure of the binder's quality. Though this is one of the crucial ones, it is not always the most important characteristic the manufacturers focus on. Depending on the product and the manufacturing technology, the IB might receive a minor consideration. The results of the IB test are presented in figure 4. These results show that the Robinia-based variant bonded with UF resin performed better than those with the industrial-based variant $\left(0.55 \mathrm{~N} / \mathrm{mm}^{2}\right.$ with UF K350 and $0.44 \mathrm{~N} / \mathrm{mm}^{2}$ with UF K340 for the Robinia-based boards compare to $0.37 \mathrm{~N} / \mathrm{mm}^{2}$ with UF K350 and $0.35 \mathrm{~N} / \mathrm{mm}^{2}$ with UF K340 for the industrial particle-based boards). The IB strength values of these board variants exceeded the EN 312 standards by $57.14 \%$ and $25.71 \%$ for K350-bonded and K340-bonded respectively. Though they contained some resin residue from previous manufacturing processes, the industrial particles could not perform better than the fresh Robinia wood material. Albumin and PMDI variants had the lowest IB values $\left(0.17 \mathrm{~N} / \mathrm{mm}^{2}\right.$ with albumin and $0.25 \mathrm{~N} / \mathrm{mm}^{2}$ with PMDI for the Robinia-based variant). All particleboards bonded with albumin and the Robinia-based bonded with PMDI produced IB values under the EN $312\left(0.35 \mathrm{~N} / \mathrm{mm}^{2}\right)$ standards.

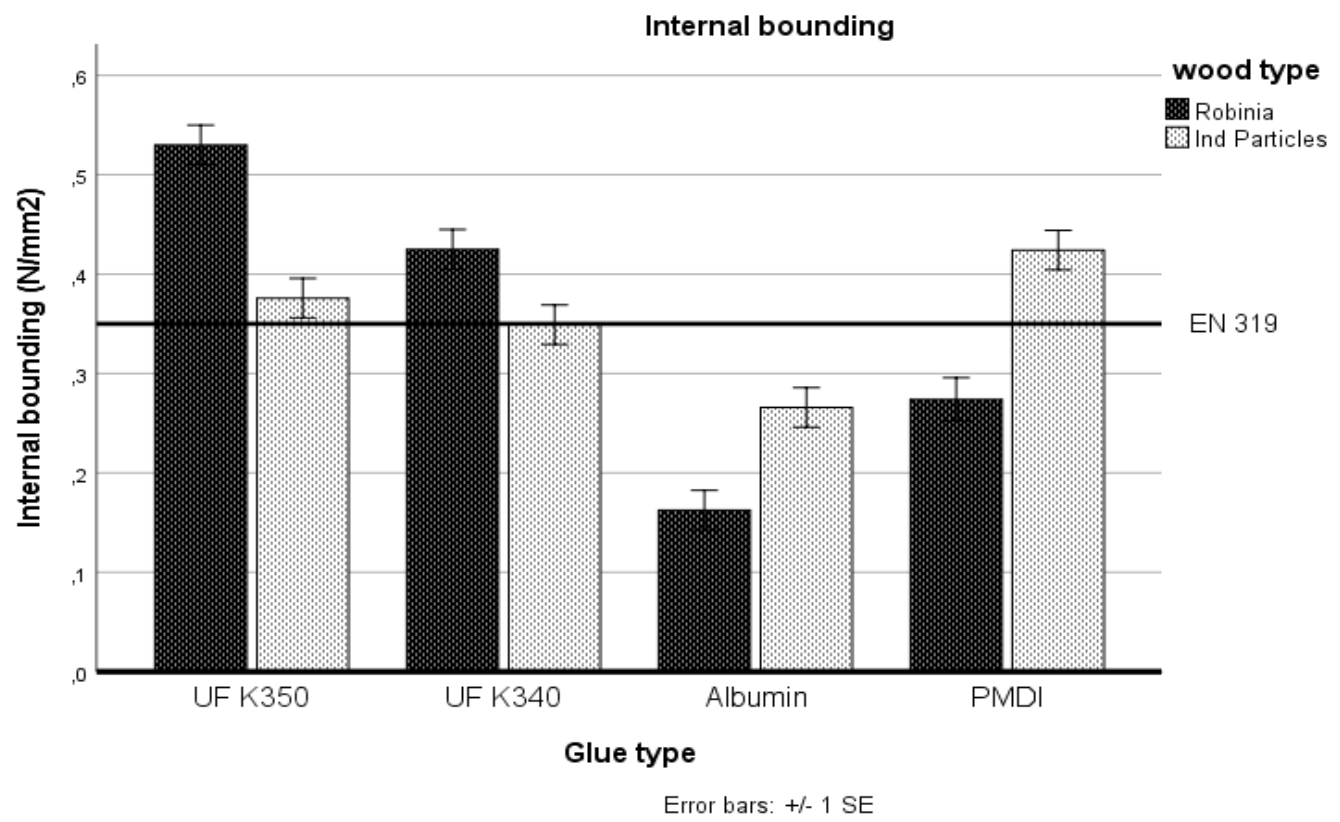

Figure 4. Internal bonding of the laboratory particleboards

\subsection{Physical Properties}

Basically, all physical and mechanical properties of wooden materials (MOE, MOR, IB, hardness, thermal conductivity, etc.) are strongly affected by the equilibrium moisture content. Above the fiber saturation point, changes in the dimensions of the wood and wood-based products begin to occur. Because of the void spaces in the particleboards, water uptake, as well as the thickness swelling is greater in the wood-based composites than in the solid wood. As expected, the Robinia-based boards proved to be more hydrophilic (figure 5). The WA and the TS of these boards were higher than in the industrial particle-based boards. Most sensitive were albumin-bonded boards which had the highest WA ( $84.0 \%$ for the Robinia-based and $77.5 \%$ for the industrial particle-based) and TS (36.2\%) for the Robinia-based and $26.5 \%$ for the industrial particle-based). Lowest values were obtained with PMDI-bonded boards, with a WA value of $42.0 \%$ for the Robinia-based and $36.7 \%$ for the industrial particlebased, and TS $13.5 \%$ for the Robinia-based and $11.3 \%$ for the industrial particle-based. According to the EN 312 , the maximum thickness swelling (TS) requirement after $24 \mathrm{~h}$ immersion in water is $15 \%$. Only the PMDI-bonded boards could fulfill this requirement. 

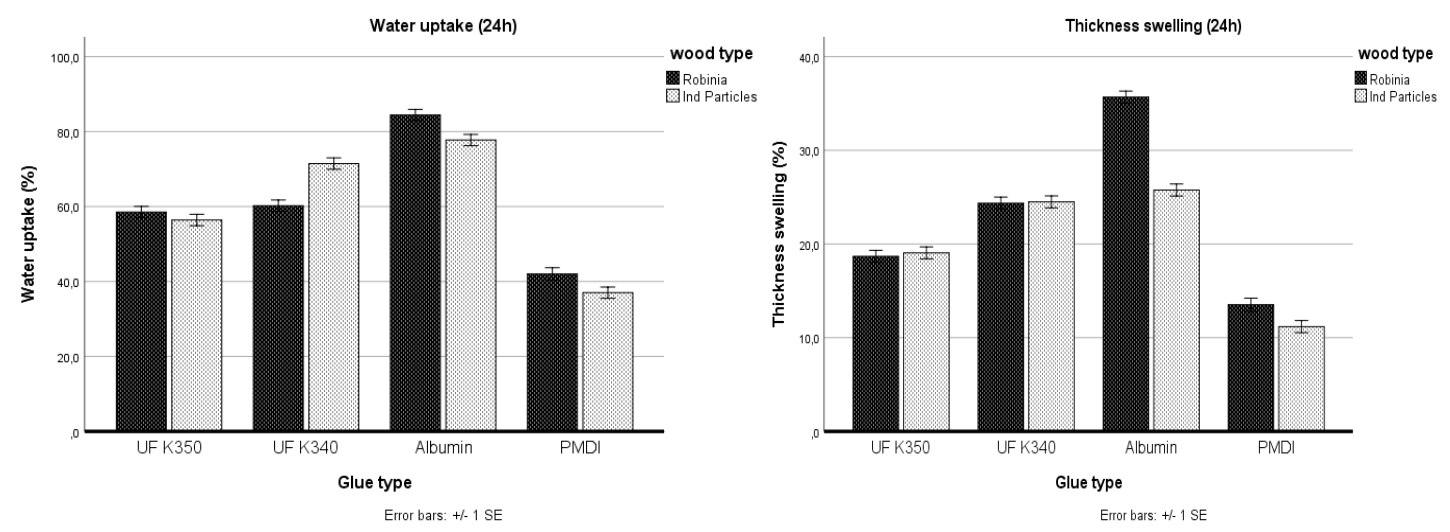

Figure 5. Water uptake and thickness swelling of the laboratory particleboards

Because of the high density in the surface layer (compares to the core layer), water uptake in particleboards is mostly through the edges. Above the FSP, the compaction ratio and the particle size have a great impact on water uptake. The smaller the particle, the smaller the voids created within the board and the lower the water absorption and thickness swelling. The amount of swelling that occurs in wood because of hygroscopic expansion is dependent on the density of the wood (Stamm, 1964). The use of hardwood-based (high-density material) results in a lower compaction ratio in the particleboards compared to softwood-based boards of the same target density. More void spaces are then created in hardwood boards and they are likely to take up more water and also swell more. This explains the results obtained here. The type of binder and additives used also highly influence the relationship of the board with water. Also, Wax and extractive content of wood can have a large effect on the sorption isotherm (Rowell, 2005), thus affecting the particleboard's reaction to water.

\subsection{Formaldehyde Content and Emission from Developed Particleboards}

Investigation of formaldehyde content using the perforator method showed a difference in formaldehyde content across the different binders (figure 6). The highest values of formaldehyde were obtained from the UF K350bonded particleboards $(4.9 \mathrm{mg} / 100 \mathrm{~g}$ for the Robinia variant and $5.1 \mathrm{mg} / 100 \mathrm{~g}$ for the industrial particle variant), followed by UF K340 with $3.2 \mathrm{mg} / 100 \mathrm{~g}$ for both variants and PMDI $(0.9 \mathrm{mg} / 100 \mathrm{~g}$ for the Robinia variant and $1.6 \mathrm{mg} / 100 \mathrm{~g}$ for the industrial particle variant). Lowest values were obtained with albumin $(0.2 \mathrm{mg} / 100 \mathrm{~g}$ for the Robinia variant and $1.5 \mathrm{mg} / 100 \mathrm{~g}$ for the industrial particle variant). This last binder gives an idea of the raw material formaldehyde content since it is completely formaldehyde-free. Across wood species, there was no significant difference in formaldehyde content in particleboards bonded with UF K350, as well as with those bounded with UF K340. The general trend across the different binders used showed lower formaldehyde content in the Robinia particleboard variant. This means the use of Robinia in the wood-based panels industry might help to minimize formaldehyde emissions and contribute to the development of more health-friendly products.

In particleboards bounded with albumin and PMDI, the industrial particle-based showed higher values of formaldehyde content than the Robinia-based ones. However, values of formaldehyde content in all particleboards from both variants were under the value $(6.5 \mathrm{mg} / 100 \mathrm{~g})$ allowed by the European standard. FC in particleboards has proven to be affected by some production parameters such as temperature, type of binder, press time. Moreover, the interaction of the formaldehyde present in the adhesive with each wood species and the anatomy of the respective wood species affect FE and FC values (Salem et al., 2012). This might explain the results obtained with albumin and PMDI where we got values of $0.2 \mathrm{mg} / 100 \mathrm{~g}$ and $1.5 \mathrm{mg} / 100 \mathrm{~g}$ with the Robinia but $0.9 \mathrm{mg} / 100 \mathrm{~g}$ and $1,6 \mathrm{mg} / 100 \mathrm{~g}$ with the industrial particles respectively.

Formaldehyde emission (FE) values followed the same trend as the perforator values (figure 7). The highest FE values were observed with UF K350 (45.8 mg/1000 g for the Robinia variant and $40.9 \mathrm{mg} / 100 \mathrm{~g}$ for the industrial particle variant). Following was UF K340 with values of $35.0 \mathrm{mg} / 1000 \mathrm{~g}$ for the Robinia variant and $29.6 \mathrm{mg} / 1000$ $\mathrm{g}$ for the industrial particle variant. Lowest FE values, again as expected, were obtained with albumin which had $0.3 \mathrm{mg} / 1000 \mathrm{~g}$ for the Robinia variant and $12.3 \mathrm{mg} / 1000 \mathrm{~g}$ for the industrial particle variant. PMDI gave FE values of $1.0 \mathrm{mg} / 1000 \mathrm{~g}$ for the Robinia variant and $13.6 \mathrm{mg} / 1000 \mathrm{~g}$ for the industrial particle variant. However, it was observed that in particleboards bonded with UF resins, the Robinia-based had higher FE compared to the industrial particle-based boards, while the FC in those two variants were the same. It can be observed that FE values from the Robinia-based boards bounded with albumin and PMDI are proportionally lower than those observed from 
their fellow industrial particle-based. High FC and FE observed in the industrial particle-based boards bounded with albumin and PMDI result from the resin contained in the raw material. These particles come from recycled furniture and construction materials which had already some glue residues from previous manufacturing processes.

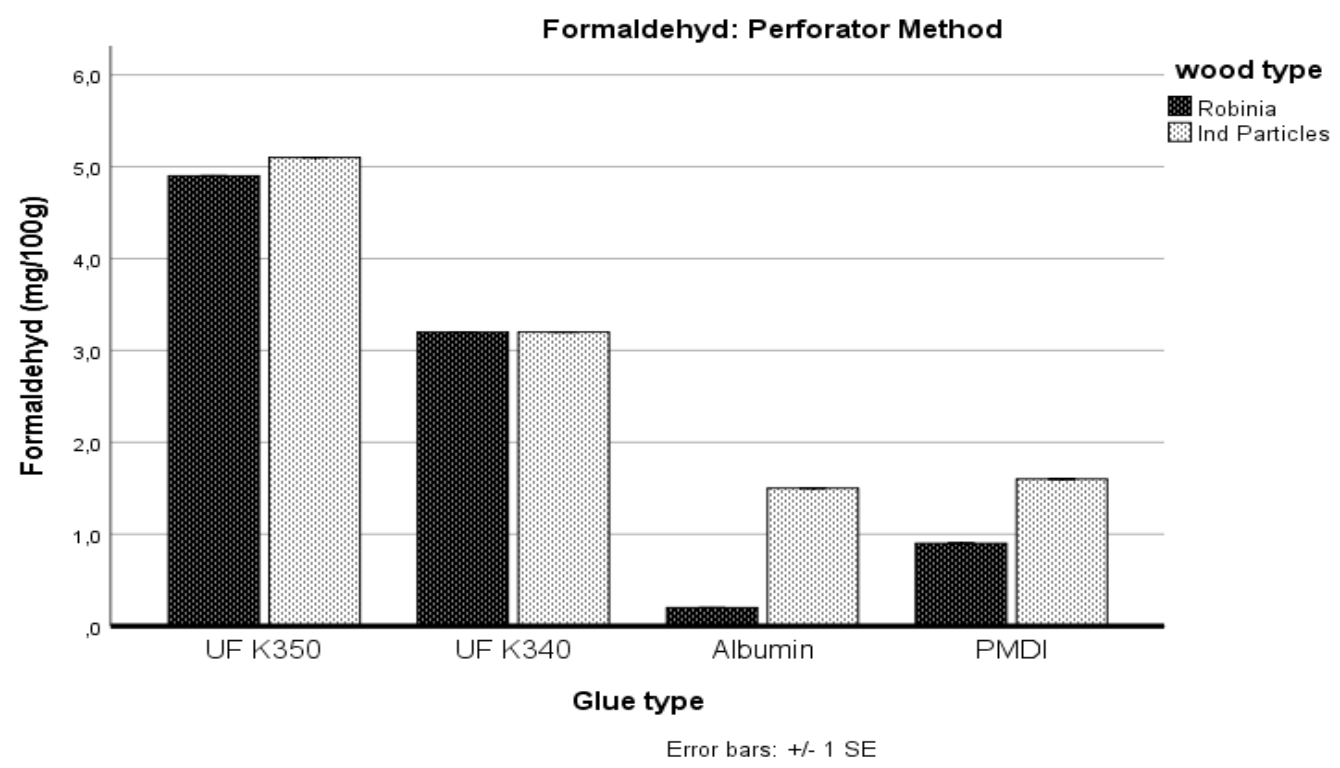

Figure 6. Extractable formaldehyde content of the developed particleboards

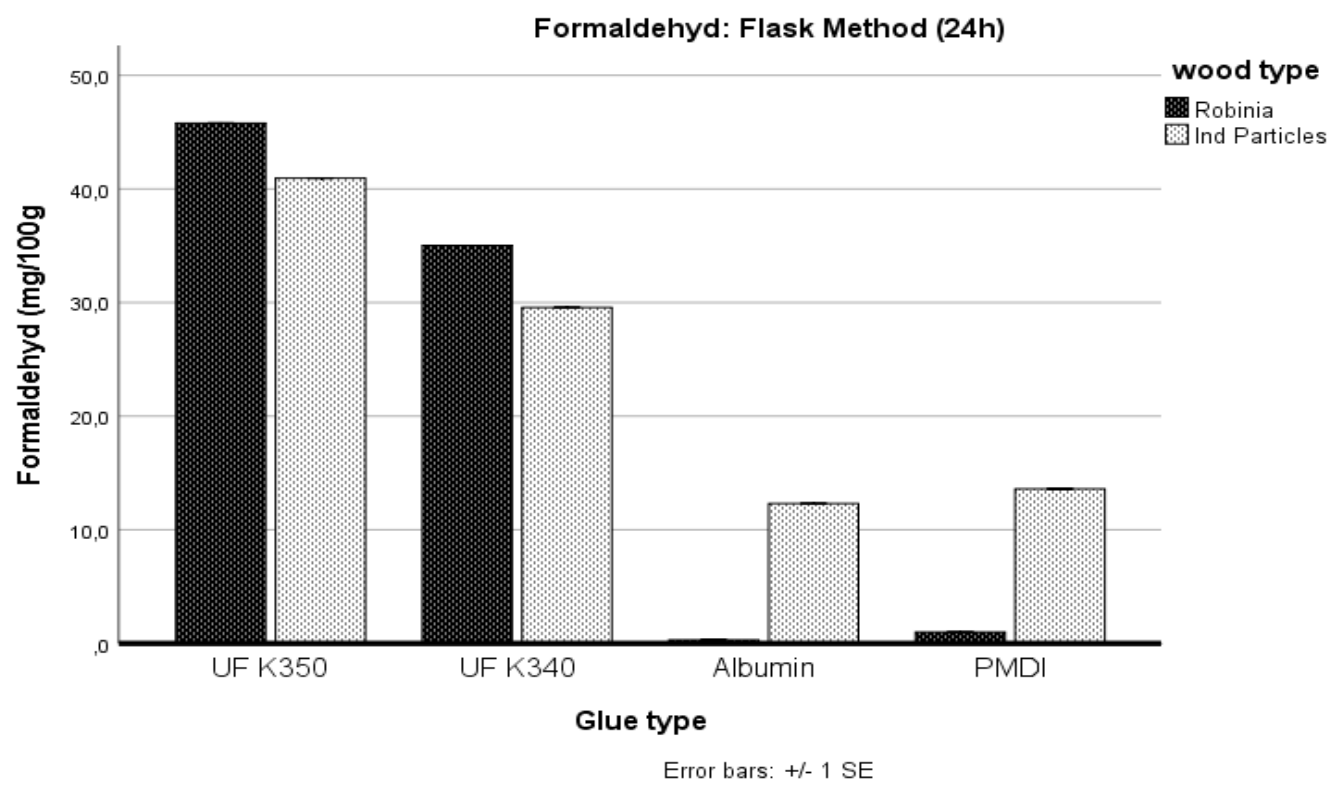

Figure 7. Formaldehyde emission from the developed particleboards

The results obtained here are comparable to the findings of Roffael et al. (2010) while remaining lower in albumin and PMDI-bounded boards. The FC values obtained in the present study were lower than the $7.92 \mathrm{mg} / 100 \mathrm{~g}$ value obtained by Salem et al. (2012) from the industrially produced Northway spruce-based particleboards of approximately the same thickness. The FC value obtained with particleboards bonded with albumin were similar to those obtained by Schmidt (2019). Frihart et al. (2012) also obtained similar figures using a no-addedformaldehyde (NAF) Soyad adhesive technology. 


\section{Conclusion}

Investigating the suitability of the fast-growing black locust young stems from the short-rotation plantation for particleboard production was the objective of this research. Six-year-old black locust stems were harvested and used to produce three-layer particleboards of $650 \mathrm{~kg} / \mathrm{m}^{3}$ density. Four types of resins: the UF K 350, the UF K 340, the albumin and the PMDI were used in a laboratory scale to produce four variants of particleboards. Reference particleboards were produced under the same conditions using industrial particles.

The IB results of all the UF resins-bonded boards fulfilled the EN 319 standards for P2 particleboards. Though the industrial particles already contained some element of glue from previous manufacturing processes, Robinia-based particleboards bonded with UF-resins had higher IB values than the industrial particle-based boards. On the contrary, the Robinia particle-based boards bonded with albumin and PMDI had lower IB values compare to their homologs, which values were found to be under the EN 319 norms.

Apart from the PMDI-bonded variants, all the other boards had the thickness selling values higher than $15 \%$ of the initial board thickness after $24 \mathrm{~h}$ of immersion in water. However, the Robinia-based and the industrial particles-based boards bonded with the UF K350 had the same swelling values, as well as those bonded with the UF K340.

Most interesting were the results of formaldehyde emission and formaldehyde content of the produced particleboards which had values lower the EN requirements. Robinia particles-based boards bonded with the UF K350 and the UF K340 contained relatively the same amount of formaldehyde than the industrial particles-based boards, while having less with albumin- and PMDI- bonded boards. As for the formaldehyde emission, Robinia particles bonded with the UF K350 and the UF K340 emitted more than their industrial fellows, but with albumin and PMDI, less emission was observed in Robinia-based boards.

The results of the present work show the high potential of black locust material from short-rotation plantation for particleboard development. Due to its adaptability to poor soil and its fast-growing potential, Black locust could be one of the future alternatives for the wood-based panel industries. Most interesting is the possibility of using natural binders such as albumin to produce environmentally friendly products. However, albumin still needs to be improved in order to enable the production of boards that meet the general requirements using Robinia particles.

\section{Acknowledgements}

The Robinia wood was supplied by the Department of Forest Botany and Tree Physiology, Georg-AugustUniversity of Goettingen via the program "IMPAC 3 - Novel genotypes for mixed cropping allow for IMProved sustainable land use ACross arable land, grassland and woodland".

\section{References}

Barboutis J. A., \& Philippou J. L. (2005). Evergreen Mediterranean hardwoods as particleboard raw material. Building and Environment. doi: 10.1016/j.buildenv.2005.07.053

Barboutis, J. A., \& Philippou, J. L. (2007). Evergreen Mediterranean hardwoods as particleboard raw material. Building and Environment, 42(3), 1183-1187. https://doi.org/10.1016/j.buildenv.2005.07.053

EN 310 (1993). Wood based panels-Determination of modulus of elasticity in bending and of bending strength. European Committee for Standardisation.

EN 312 (2005) Particleboards-specifications. European Committee for Standardization, Brussels (Belgium)

EN 317 (1993) Particleboards - determination of swelling in thickness after immersing in water. European Committee for Standardization

EN 319 (1993) Particleboards - determination of tensile strength perpendicular to the plane of the board. European Committee for Standardization

EN 321. (2002) Wood-based panels - Determination of moisture resistance under cyclic test conditions. European Committee for Standardisation, Brussels.

FAO. (2009). State of the world forests. Food and Agriculture Organization of the united nations. Rome, 2009.

Friese, F., Euring, M., \& Kharazipour, A. (2015). Particleboards from Newly Exploited Wood Sourcesas a Starting Point for Cascade Utilisation. In D. B. Manning, A. Bemmann, M. Bredemeier, N. Lamersdorf, \& C. Ammer (Eds.), Bioenergy from Dendromass for the Sustainable Development of Rural Areas (pp. 497-506). https://doi.org/10.1002/9783527682973.ch36

Frihart, C. R., Wescott, J. M., Chaffee, T. L., \& Gonner, K. M. (n.d.). Formaldehyde Emissions from Urea- 
Formaldehyde- and No-Added-Formaldehyde-Bonded Particleboard as Influenced by Temperature and Relative Humidity. Forest Products Journal, 62(7-8), 551-558. https://doi.org/10.13073/FPJ-D-12-00087.1

Gamage, N., Setunge, S., Jollands, M., \& Hague, J. (2009). Properties of hardwood saw mill residue-based particleboards as affected by processing parameters. Industrial Crops and Products, 29, 248-254.

Kharazipour, A. (2005) Holz als Werkstoff. In: Jahrbuch Nachwachsende Rohstoffe, 2004/2005. Herausgeber: CARMEN e.V.

Manning, D. B., Bemmann, A., Bredemeier, M., Lamersdorf, N., \& Ammer, C. T. S.-C. M.-C. (Eds.). (2015). Bioenergy from Dendromass for the Sustainable Development of Rural Areas. Weinheim, Germany: Wiley$\mathrm{VCH}$ Verlag GmbH \& Co. KGaA.

Mantau U., Saal U., Prins K., Steierer F., Lindner M., Verkerk H., Eggers J., Leek N., Oldenburger J., Asikainen A., \& Anttila P. (2010): EUwood - Real potential for changes in growth and use of EU forests. Final report. Hamburg/Germany, June 2010. 160 p.

Roffael, E., Johnsson, B., \& Engström, B. (2010). On the measurement of formaldehyde release from low-emission wood-based panels using the perforator method. Wood Science and Technology, 44(3), 369-377. https://doi.org/10.1007/s00226-010-0355-1

Rofii, M. N., Yumigeta, S., Kojima, Y., \& Suzuki, S. (2014). Utilization of High-density Raw Materials for PanelProduction and its Performance. Procedia Environmental Sciences, 20, 315-320. https://doi.org/10.1016/j.proenv.2014.03.039

Rowell, R. M., Pettersen, R., Han, J. S., Rowell, J. S., \& Tshabalala, M. A. (2005). Cell wall chemistry. In M. Roger \& M. Rowell (Eds.), Handbook of wood chemistry and wood composites. Includes bibliographical references and index.

Rowell, R. M. (n.d.). Handbook of wood chemistry and wood composites. Boca Raton, Fla.; London TS - The British Library.

Salem, M. Z. M., Böhm, M., Srba, J., \& Beránková, J. (2012). Evaluation of formaldehyde emission from different types of wood-based panels and flooring materials using different standard test methods. Building and Environment, 49, 86-96. https://doi.org/10.1016/j.buildenv.2011.09.011

Schmidt P. (2019). Blutalbumin gebundene Spanplatten aus geringwertigen Launholzsortimenten (Unpublished Master‘s Thesis), Fakultät für Forstwissenschaften und Waldökologie der Georg-August Universität Göttingen-Deutschland.

Stamm, A. J. (1964). Measurement of pH. Para. 10.1. Selective adsorption from solutions. Chapter 10. Wood and cellulose science. The Ronald Press Company, NY.

Thoemen, H., Irle, M., \& Sernek, M. (2010). Wood-based panels. Retrieved from http://www.worldcat.org/oclc/731238246

Wilczyński, A., \& Kociszewski, M. (2012). Elastic properties of the layers of three-layer particleboards. European Journal of Wood and Wood Products, 70(1-3), 357-359. https://doi.org/10.1007/s00107-010-0497-8

Wimmer R., Weigl M., \& Schöneberg S. (2011). Particle Boards Made from Hardwoods - What is the Significance? Proceedings of the 3rd International Scientific Conference on Hardwood Processing (ISCHP 32011) I: Peer reviewed contributions October 16 - 18, 2011 Blacksburg, Virginia, USA

\section{Copyrights}

Copyright for this article is retained by the author(s), with first publication rights granted to the journal.

This is an open-access article distributed under the terms and conditions of the Creative Commons Attribution license (http://creativecommons.org/licenses/by/4.0/). 